\title{
EFEITOS PLEIOTRÓPICOS DO GENE MERLE EM CÃES - REVISÃO
}

\author{
FERREIRA, Nalva de Fátima ${ }^{1}$ \\ MANGOLIN, Letícia Fornel ${ }^{2}$ \\ CAMINHAS, Maria Margareth Theodoro ${ }^{3}$
}

\begin{abstract}
Recebido em: 2020.04.23 Aprovado em: 2020.11.27
ISSUE DOI: $10.3738 / 21751463.3779$

RESUMO: Atualmente, há uma grande demanda por características estéticas que sejam lucrativas no mercado pet, evidenciado pelo aumento crescente do número de animais no país, de acordo com as pesquisas. Um dos padrões raciais desejados em cães é o padrão merle, onde apresenta-se como uma pelagem semelhante a mármore, devido a influência do gene M (merle), sendo esse tipo de coloração aparente em diversas raças. Sabendo disso, objetiva-se com o presente trabalho realizar uma revisão quanto a influência do gene merle e as patologias associadas, e comparar com outras anomalias que possuem influência genética das pelagens. Haja vista essas características fenotípicas, os animais portadores dessa linhagem genética oferecem o risco de gerar animais a maior possibilidade de déficit auditivo, quando comparado à cães da mesma raça, porém com outros padrões de cores. Além disso, como resultado do cruzamento entre dois animais de pelagem merle, há a possibilidade da geração de filhotes portadores da síndrome do duplo merle, cuja condição é associada a uma série de patologias concomitantes como surdez, cegueira, esterilidade entre outras, que podem ser incompatíveis com a vida. Com isso, é de extrema importância conhecer sobre os possíveis riscos e prejuízos que podem ocorrer de um cruzamento realizado de forma irracional. Portanto, é de responsabilidade do médico veterinário a instrução quanto a reprodução comercial da espécie, de modo a promover a educação dos tutores e criadores, e a manutenção do bem-estar dos cães.
\end{abstract}

Palavras-chave: Genética, Pelagem, Fenótipo, Alelo, Surdez.

\section{PLEIOTROPIC EFFECTS OF THE MERLE GENE ON DOGS - REVIEW}

SUMMARY: Currently, there is a great demand for aesthetic characteristics that are profitable in the pet market, evidenced by the increasing number of animals in the country, according to research. One of the desired racial patterns in dogs is the merle pattern, where it appears as a coat like marble, due to the influence of the $\mathrm{M}$ (merle) gene, this type of color being apparent in several breeds. Knowing this, the objective of this study is to carry out a review regarding the influence of the merle gene and the associated pathologies, and to compare it with other anomalies that have a genetic influence on the coat. Thinking about of these phenotypic characteristics, animals carrying this genetic offer the risk of generating animals with the greatest possibility of hearing loss, when compared to dogs of the same breed, but with other color patterns. In addition, as a result of the cross between two merle coat animals, there is the possibility of the generation of puppies with double merle syndrome, whose condition is associated with a series of concomitant pathologies such as deafness, blindness, sterility, among others, which can be incompatible with life. With this, it is extremely important to know about the possible risks and losses that can occur from a reproduction carried out irrationally. Therefore, it is the responsibility of the veterinarian to instruct on the commercial reproduction of the species, in order to promote the education of tutors and breeders, and the maintenance of the welfare of dogs.

Keywords: Genetics, Coat, Phenotype, Allele, Deafness

\section{INTRODUÇÃO}

A maior parte das raças caninas surgiu a partir do interesse humano, de acordo com a sua necessidade, para fins como companhia, caça, segurança, pastoreio e até estético

\footnotetext{
${ }^{1}$ Graduanda do Curso de Medicina Veterinária da Universidade Estadual Paulista (UNESP), Faculdade de Medicina Veterinária, Campus Araçatuba (SP)

${ }^{2}$ Graduanda do Curso de Medicina Veterinária da Universidade Estadual Paulista (UNESP), Faculdade de Medicina Veterinária, Campus Araçatuba (SP)

${ }^{3}$ Departamento de Produção e Saúde Animal - FMVA/Unesp - Araçatuba, SP
}

Nucleus, v.12, n.2, nov. 2020 
(BERTIPAGLIA, 2010). Por causa dos inúmeros cruzamentos realizados, permitiu-se o desenvolvimento das raças atuais, porém, com o melhoramento sendo empregado de forma desmedida, contribuiu para mudanças anatômicas e fisiológicas nos animais (SORIANO, 2014), de modo que, esses animais não têm mais a possibilidade de voltar para o meio ambiente.

Quanto maior a demanda por animais melhorados geneticamente e seleção de determinadas características, maior e mais frequente se tornarão as anomalias, cujo agravante é que, nem todas essas patologias são expressas através de sintomatologias clínicas. A exemplo de consequências da seleção desses problemas podemos citar as anomalias cardíacas, déficit visual e diabetes (ROONEY, 2009).

O mercado pet vem demonstrando resultados crescentes no âmbito econômico nacional, conforme dados apresentados pelo Instituto Pet Brasil (IPB). De acordo com o IPB, o país tem alta representatividade mundial, ocupando a posição de segundo maior comércio, atrás apenas dos Estados Unidos, apresentando resultados acima do Produto Interno Bruto mesmo em momentos de crise nacional, como ocorrida em 2018.

Tabela 1 - População de animais no Brasil em milhões em 2018, de acordo com a espécie.

\begin{tabular}{cc}
\hline Espécie animal & População em milhões \\
\hline cães & 54,2 \\
gatos & 23,9 \\
peixes ornamentais & 19,1 \\
aves canoras e ornamentais & 39,8 \\
outros & 2,3 \\
\hline
\end{tabular}

Fonte: Abinpet, 2018.

Dada a importância do setor na economia, avanços vêm sendo observados no que se refere principalmente a saúde e bem-estar dos animais que são submetidos à reprodução por criadores. Esse fato é evidenciado com a elaboração do manual de boas práticas para criação de animais de estimação, disposto em 2019 pelo Ministério da Agricultura, Pecuária e Abastecimento (MAPA).

Uma vez que a venda de filhotes de certas raças e linhagens vem apresentando alta demanda, aumentou-se o interesse de criadores em reproduzir e manter certas características que determinam os padrões raciais que são considerados atraentes e que, por consequência geram lucro. Para que essa prática seja possível, muitos criadores recorrem ao cruzamento de animais com primeiro grau de consanguinidade, tornando a variabilidade genética escassa e aumentando a ocorrência de mutações (MEYERS-WALLEN, 2003). 
Segundo Otto (2012), a técnica da endogamia quando utilizada serve para assegurar uma característica pela qual se tem interesse em passar para os descendentes. Porém, ao ser aproveitada em cruzamentos, é considerada de alto custo se comparada ao benefício, sabendo que é necessário a intervenção a fim de evitar genes indesejáveis. Isso ocorre uma vez que, o endocruzamento leva a redução da heterozigose, e isso aumenta a possibilidade de genes que antes eram mascarados por outros à aparecer. Portanto, essa técnica leva a diminuição do vigor, levando a chamada de depressão endogâmica, o que não é de interessante para o criador. De acordo com Otto (2012), a depressão endogâmica irá ocorrer nos genes que levam ao melhoramento do desempenho, quanto maior a média dos homozigotos, maior essa depressão.

O padrão de pelagem do merle é reconhecida em algumas raças no Brasil porém, falta fiscalização por parte de órgãos oficiais. Uma análise feita em Minas Gerais com 40 cães Border Collie, 15 apresentando o padrão merle, apenas 7 possuiam registro de Pedigree (DE SOUZA et al., 2018). O gene merle está associado a problemas de saúde, mortalidade, surdez, cegueira e diminuição da qualidade de vida dos animais, principalmente em casos de cruzamentos endogâmicos como é comum ocorrer dentro de criadores, logo, a baixa fiscalização é um agravante pois dão margem à falhas quanto ao modo de criação o mais ético possível, seja por falta de informação ou por negligência

Portanto, devido a relevância do tema, objetivou-se buscar informações quanto a influência do gene merle e as patologias associadas, e comparar com outras anomalias que possuem influência genética das pelagens.

\section{O GENE M}

O lócus do gene $\mathrm{M}$ em cães é formando por dois alelos: um M que é caracterizado por codificar a distribuição aleatória de cores na pelagem, levando a áreas de diluição do pigmento juntamente com áreas de melanina normais (CLARK et al., 2006), alterando também a cor dos olhos e do nariz (STRAIN, 2009).

Essa condição e regulação é resultado da inserção de uma retroposição de cauda mononucleotídica específica poli(A) do merle-SINE (elemento nuclear curto intercalado), que é uma alteração caracterizada pela repetição de derivados de tRNA canino específico no locus do gene SILV, também conhecido como PMEL - que é expressado na pigmentação dos mamíferos por estar presente no processo fisiológico de melanogênese que consiste na síntese de melanina (VARGA et al., 2020), resultando, portanto, na disfunção das células produtoras da pigmentação em mamíferos (CLARK et al., 2006, PELLES et al., 2019,). O “M”, tem origem na mutação de 
genes pleiotrópicos identificado no cromossomo canino 10 (CFA10) de caráter autossômico de dominância incompleta (STRAIN, 2015).

Sendo assim, as características fenotípicas conhecidamente geradas pelo alelo responsável por esse gene em ninhadas caninas fornece um tipo de cobertura de pelagem que ocorre em diversas raças, como o Daschund, American Kennel Club, Shetland Sheepdog, Australian Shepherd, Cardigan Welsh Corgi (CLARK et al., 2006).

\section{REPRODUÇÃO}

Os cães portadores dos genes MM apresentam a alterações patológicas em olhos, formação estrutural e funções auditivas, dentre outras anomalias que impossibilitam o desenvolvimento e a vida desses animais (ClARK et al., 2006). O indivíduo duplo merle (MM) é obtido através do cruzamento entre dois animais portadores do gene $\mathrm{M}$ - vale ressaltar que o gene M pode estar presente em animais não possuintes das características típicas de um merle probabilisticamente $75 \%$ da prole advindo desse cruzamento serão cães saudáveis, $50 \%$ em heterozigose apresentando as características do merle e os outros $25 \%$ serão cães sem essas características fenotípicas, entretanto, $25 \%$ dos filhotes poderão apresentar a síndrome do duplo merle, logo, esse tipo de cruzamento é oficialmente proibido. O acasalamento de um cão M com outro cão homozigoto recessivo "mm" impede a ocorrência de indivíduos duplo Merle, resultando em $50 \% \mathrm{~mm}$ e $50 \% \mathrm{Mm}$ (VARGA et al.2020)

Todavia, problemática do gene merle não se limita apenas aos cães que possuem a cobertura de pêlos característica, mas se estende também há animais que podem possuir coloração de pelagem não usual ao fenótipo e, mesmo assim, possuírem o gene que pode ser passado à prole gerando os danos ligados ao duplo merle. Os chamados criptico, arlequim e diluído, onde o críptico no geral apresenta pelagem preta sem evidencia de merle, o arlequim branco com manchas de pigmentação completa e o diluído com pelagem uniforme cinza-aço (MURPHY et al. 2018; LANGEVIN et al.2018).

Vários casos de patologias relacionadas a genética das pelagens já foram descritos na literatura, não se limitando, portanto, ao gene merle, evidenciando a importância da realização de cruzamentos de forma racional.

O médico veterinário possui o papel de educar os tutores de cães quanto a reprodução desses animais, de modo a indicar os possíveis riscos de se realizar o cruzamento de animais portadores desse mesmo alelo. 


\section{SURDEZ CONGÊNITA}

De acordo com Strain (1999), os cães que possuem a síndrome do duplo merle (homozigotos para o gene $\mathrm{M}$ ) apresentam predominantemente a pelagem branca, déficit reprodutivo, visual e auditivo, enquanto, os animais merle (heterozigotos para o gene M) possuem a tendência maior a apresentarem algum grau de surdez. A degeneração da parede do ducto coclear com evolução até o sáculo e parede da mácula levando a surdez também está associada a alterações congênitas vinculadas a cor branca de pelagem devido à ausência de pigmento em animais com a presença de melanócitos afuncionais, ou seja, não produtores de melanina em algumas raças da espécie canina, gatos brancos, humanos e camundongos (STRAIN, 1999).

Há na literatura, relatos de casos de surdez raça-específica, prevalente em Dalmatas, Bull Terrier, English Setter, English Cocker Spaniel, Australian Cattle Dog, Catahoula Cattle Dog e Jack Russell Terrier, embora nem todos apresentem hereditariedade e uma grande parte apresentem a coloração branca (STRAIN, 1999). Ainda de acordo com Strain, 1999, uma pequena parte dos animais afetados não apresentam coloração branca, como nas raças que apresentam os genes merle e piebald. Esses genes, quando codificam para seu respectivo padrão de pelagem, desequilibram a endolinfa presente no sistema auditivo provocando a surdez no cão afetado. Isso ocorre devido à falta de suprimento sanguíneo na região da cóclea (STRAIN, 1999).

Em relação à surdez congênita, existem várias formas de atestar quanto a existência ou não de déficits auditivos em cães, uma delas consiste na análise comportamental frente a estímulos sonoros. Animais que não apresentam a audição bilateral são incapazes de detectar o local de origem do som, embora possam vir a se adaptar com o tempo (STRAIN, 2015).

Há exames médicos como o Teste de BAER e teste PEATE, que permite reconhecer se há déficits auditivos. O PEATE (potencial evocado auditivo de tronco encefálico) é um método não invasivo e objetivo, que permite avaliar alterações auditivas, tipo de perda auditiva e alterações do sistema nervoso central desde o nervo auditivo até o tronco encefálico por meio de ondas de latência do potencial auditivo (ESTEVES, et.al, 2009). Exatamente por ser tratar de métodos seguros, são amplamente utilizado por médicos veterinários na Europa e América do Norte para determinar a funcionalidade e limiar auditivo além da inspeção do animal, no Brasil por outro lado, ainda é pouco utilizado na Veterinária (STEFANELLO, 2017).

Na raça boiadeiro-australiano, Sommerlad et al,(2010), testaram 315 animais para surdez e identificaram que, 17,8\% desses apresentavam algum grau de déficit auditivo, sendo que, aqueles que apresentassem pigmentação vermelha na pelagem apresentavam de forma significativa $(\mathrm{p}=0,045)$ a possibilidade de dano auditivo quando comparado a animais de 
pigmento azul. O estudo salienta o mapeamento do CFA-10 - cromossomo associado a morfologia da orelha - onde demonstrou-se possível associação com a surdez.

Comito et al, em 2012 analisaram a associação entre a surdez congênita e o fenótipo de cães Jack Russel Terrier, no estudo, observou-se que houve diferença significativa entre os animais que possuíam pelo branco e/ou pais com déficits auditivos, descartando a influência do sexo e da textura de pelagem, e apoiando-se por outro lado, na associação de uma hereditariedade ligada aos genes de pigmentação.

Tabela 2 - Associação entre a porcentagem de animais com déficit auditivo e o padrão de pelagem merle.

\begin{tabular}{cccc}
\hline Número de animais & Raça & Porcentagem de Surdez & Autor \\
\hline 153 & 10 raças puras e 1 mista & $3,5 \%$ & Strain et. al, 2009 \\
339 & Border Collie & $7,4 \%$ & Risio et al, 2011 \\
163 & Border Collie & $20,7 \%$ & Platt et al, 2006 \\
\hline
\end{tabular}

Fonte: Strain et. al, 2009; Risio et al, 2011; Platt et al, 2006

Nos estudos de Strain et al., 2009, analisou-se o padrão de pelagem merle envolvendo diferentes raças (Catahoula, Australian Shepherd, Chihuahua, Collie, Shetland Sheepdog, Cardigan Welsh Corgi, Great Dane, Border Collie, Dachshund, Cocker Spaniel e um cão de raça mista), de ambos os sexos. Observou-se que houve diferença significativa entre os animais merles e não merles, porém, de acordo com os autores, não relação entre o sexo do animal e cor dos olhos.

De acordo com Risio et al, (2011), houve correlação significativa entre os cães estudados da raça Border Collie, o déficit auditivo em animais de olhos azuis e animais com o padrão merle. Esses resultados concordam com os estudos de Platt et al, (2006), onde demonstrou-se que houve correlação significativa também entre os cães dessa mesma raça, porém, Platt et al, 2006 também mencionam que as taxas foram maiores entre os animais que apresentaram coloração branca na cabeça em comparação aos animais com audição normal.

\section{CONCLUSÃO}

Conclui-se que é de grande importância a atuação e intervenção do médico veterinário na defesa do bem-estar animal, auxiliando para que seja feita uma reprodução consciente e segura com orientação profissional. Com isso, sempre que possível, deve-se realizar um detalhado registro de árvore genealógica para evitar não só as mutações que podem acometer animais Nucleus, v.12, n.2, nov. 2020 
portadores do gene "M", mas também outras patologias que apresentam a genética como desencadeadora. Apesar de atualmente a literatura ainda ser escassa sobre o tema merle e sua ligação com certas patologias, o desenvolvimento dessa revisão buscou sintetizar e aprofundar o tema no objetivo de facilitar futuras pesquisas.

\section{REFERÊNCIAS}

ABINPET. Disponível em: http://abinpet.org.br/mercado/ Acesso em 03 de abril de 2020.

BERTIPAGLIA, T. S.; GOMES, F.J. "Melhoramento genético de cães". Universidade Estadual Paulista - "Júlio de Mesquita Filho" Universidade Estadual Paulista, p.31, 42-43, 2010.

CLARK, L. A. et al. "Retrotransposon Insertion in SILV Is Responsible for Merle Patterning of the Domestic Dog." Proceedings of the National Academy of Sciences of the United States of America, v.103, n.5, p.1376 - 1381, 2006.

COMITO, B. et al. Congenital deafness in Jack Russell terriers: Prevalence and association with phenotype. The Veterinary Journal, v. 193, n. 2, p.404-407, 2012.

DE SOUZA, S. L. et al. Distúrbios audiovisuais associados ao gene Merle em cães da raça Border Collie. Anais do Comeia, n.11, Patos de Minas, 2018. issn 2527- 239x, p. 1, 2018.

ESTEVES, M.C.B. et al. Estudo das latências das ondas dos potenciais auditivos de tronco encefálico em indivíduos normo-ouvintes. Brazilian Journal Otorhinolaryngology, v.75, n.3, p. 420-425, 2009.

INSTITUTO PET BRASIL. Disponível em: http://institutopetbrasil.com/ Acesso em 03 de abril de 2020.

LANGEVIN, M. et al. Merle phenotypes in dogs - SILV SINE insertions from Mc to Mh. Public Library of Science, v. 13, n. 9, p. 1-20, 2018.

MEYERS-WALLEN, V. N. Ethics and genetic selection in purebred dogs. Reproduction in Domestic animals, v.38, n.1, p. 73-76, 2003.

MURPHY, S. C. et al. Length variations within the Merle retrotransposon of canine PMEL: Correlating genotype with phenotype. Mobile DNA, v. 9, n. 1, p. 1-11, 2018.

PLATT S. et al. Prevalence of Unilateral and Bilateral Deafness in Border Collies and Association with Phenotype, Journal of Veterinary Internal Medicine, v.20, p.1355-1362, 2006.

OTTO, P.G. Genética Básica para veterinária, Ed. Roca, 5Edição, São Paulo, 2012.

PELLES, Z. et al. Merle allele variations in the Mudi dog breed and their effects on phenotypes. Acta veterinaria Hungarica, v. 67, n. 2, p. 159-173, 2019.

RISIO, L. D. Prevalence, heritability and genetic correlations of congenital sensorineural 
deafness and pigmentation phenotypes in the Border Collie. The Veterinary Journal, v. 188, p.286-290, 2011.

ROONEY, N.J. The welfare of pedigree dogs: cause for concern. Journal of Veterinary Behavior, v.4, n.5, p.180-186, 2009.

SORIANO, V.S. Seleção artificial e o bem-estar de cães. SB Rural, edição 124, p.1, 2014.

STEFANELLO, C. R. Estudo Da Via auditiva em cães beagles por meio de potenciais auditivos de tronco encefálico. Programa de pós-graduação em Ciências Veterinárias. Universidade Federal do Rio Grande do Sul Faculdade de Veterinária, 2017.

STRAIN, G.M. Canine Deafness. Veterinary Clinics of North America: Small Animal Practice, v. 42, n. 6, p.1209-1224, 2012.

STRAIN, G.M. Congenital deafness and its recognition. Veterinary Clinics Of North America: Small Animal Practice, v.29, n.4, 1999.

STRAIN, G. M. The Genetics of Deafness in Domestic Animals. Frontiers in Veterinary Science, v.2, n.29, p. 1-20, 2015.

STRAIN, G.M. et al. Prevalence of Deafness in Dogs Heterozygous or Homozygous for the Merle Allele. Journal of Veterinary Internal Medicine, v.23, n.2, p.282-286, 2009.

SOMMERLAD, S. et al. Congenital Sensorineural Deafness in Australian Stumpy-Tail Cattle Dogs Is an Autosomal Recessive Trait That Maps to CFA10. Public Library of Science, v.5, n.10, p. 1-9, 2010.

VARGA, L. et al. Being merle: The molecular genetic background of the canine merle mutation. Genes, v. 11, n. 6, p. 1-15, 2020 